\title{
EVALUATION OF DIFFERENCES IN DISTANCE LEARNING TECHNIQUES AT SELECTED UNIVERSITIES IN THE V4 REGION
}

\author{
M. Boroš ${ }^{1}$, A. Velas ${ }^{1}$, L. Christián ${ }^{2}$ \\ ${ }^{1}$ Univerzity of Zilina (SLOVAKIA) \\ ${ }^{2}$ University of Public Service (HUNGARY)
}

\begin{abstract}
The coronavirus pandemic has affected all industries worldwide and has not escaped university academia. Many universities have had to switch from full-time to distance learning over the past academic year. Security education is a specific form of education as it is a combined combination of mainly managerial, technically, and legally oriented subjects. Security education is carried out at several European universities and focuses mainly on the local, landscape-level of security.
\end{abstract}

To determine the impact of the corona crisis on teachers, a questionnaire survey was conducted, which was attended by teachers from three European countries. Specifically, these were teachers dealing with security and working at the University of Zilina (SK), the Academy of the Police Corps (SK), Tomas Bata University (CZ), and the University of public service (HU). Almost 80 teachers took part in the survey and it aimed to find out and evaluate the effectiveness of managing the distance form of teaching during the coronary crisis. From the results obtained by the survey, it was possible to point out the previous use of online forms of teaching, especially e-learning, as well as the impact of teachers' pedagogical practice on the way of communication with students. It is the parameter of using modern technologies and social networks to deepen the relationship between teachers and students that we could consider as one of the main indicators of a modern teacher. We also obtained an overview of changes in the conditions of completing the course before and during the coronary crisis, where due to the current situation, some teachers were forced to change the type of subject exam.

However, the coronacrisis and the circumstances associated with it at the named but certainly also other universities also pointed out shortcomings in the possibilities of using either online lecture programs or e-learning. These shortcomings could include the inconsistency of the use of a selected type of lecture program at a university or workplace, and especially in many cases the low level of knowledge about the use and administration of such types of programs. It would, therefore, be appropriate for all universities to invest time and money in educating their staff in online lecture programs.

In the future, in the event of a similar pandemic, but also in general, it would be appropriate to recommend a single online lecture program for the European level. The uniformity of online lecture programs would facilitate the acclimatization of foreign Erasmus + students, as they would work with a program known to them.

Keywords: Changes, e-learning, coronacrisis, online lecture program, subject exam, communication with students.

\section{INTRODUCTION}

Security can be defined from different angles, depending on the industry in which we are interested in ensuring security. Security education is also directly related to security education, which is focused on various forms of ensuring security in terms of saving lives, political security, physical protection of buildings, the technical security of buildings, and the like. Despite the current European technical standards, there is a difference in the focus of universities in security education.

Within the Slovak Republic, the Czech Republic, and Hungary, several universities deal with security. Specifically, these are the University of Žilina in Žilina, the Academy of the Police Force in Bratislava for Slovakia, Tomas Bata University in Zlín for the Czech Republic, and the National University of Public Service for Hungary. Despite these common interests, there are several differences between these universities, such as focus. In the case of the Academy of the Police Force and the National University of Public Service, the focus is primarily on police forces and regional or national security, and graduates of these schools will obtain a master's degree in the second stage of the study. In the case of the University of Žilina in Žilina and Tomas Bata University in Zlín, the study also focuses on the technical part of the security of buildings, and graduates of the second degree will acquire the title of engineer. 
Despite these differences, there are friendly relations between universities and faculties. A great advantage of the cooperation of these universities is the possibility of completing an Erasmus + internship or student stay at these universities, which will give them a more comprehensive overview of the regionally addressed issues [ $1-2-3]$.

Due to the pandemic situation caused by the coronavirus, teachers and students had to deal with the transition from full-time to distance learning. Due to its relatively rapid start-up, such a transition was certainly not easy, so we focused on finding out how teachers at selected universities managed the online form of teaching. As part of solving the problem, our goal was to find out whether the given universities use the same online programs in case of recurrence of the pandemic situation. In the solution, we also focused on the way of communication with students, as it was not possible to consult with teachers within the standard consultation hours, or after the lectures [4 -5$]$.

\section{METHODOLOGY}

In terms of efficiency, we decided to use a questionnaire survey conducted directly at the departments dealing with security. Our goal was, as already mentioned, to obtain a comprehensive assessment for the three countries. However, despite our activity, we were unable to obtain a return on the questionnaire from Tomas Bata University in Zlín.

A total of 81 respondents from three universities took part in the questionnaire survey. There were 30 of the University of Žilina in Žilina, 12 from the Police Academy, and 39 from the National University of Public Service. The questionnaire survey consisted of seven questions focused on the number of years of pedagogical practice, communication between teachers and students, situation, and the use of online lecture programs.

The questions in the questionnaire were of a mixed nature, ie open-ended questions with the possibility of the respondent's inscription, but also closed questions with the need to choose one of the predefined options. Closed questions were directed especially in the case of finding pedagogical practice so that we could reliably express the experience of respondents. We used open-ended questions mainly to find out the way of communication between teachers and students [6 -7].

\section{RESULTS}

As mentioned above, 81 respondents from three universities and colleges, respectively, participated in the questionnaire survey. At the beginning of the questionnaire we were interested in the pedagogical practice of the respondents and the results of this question are shown in Figure 1.

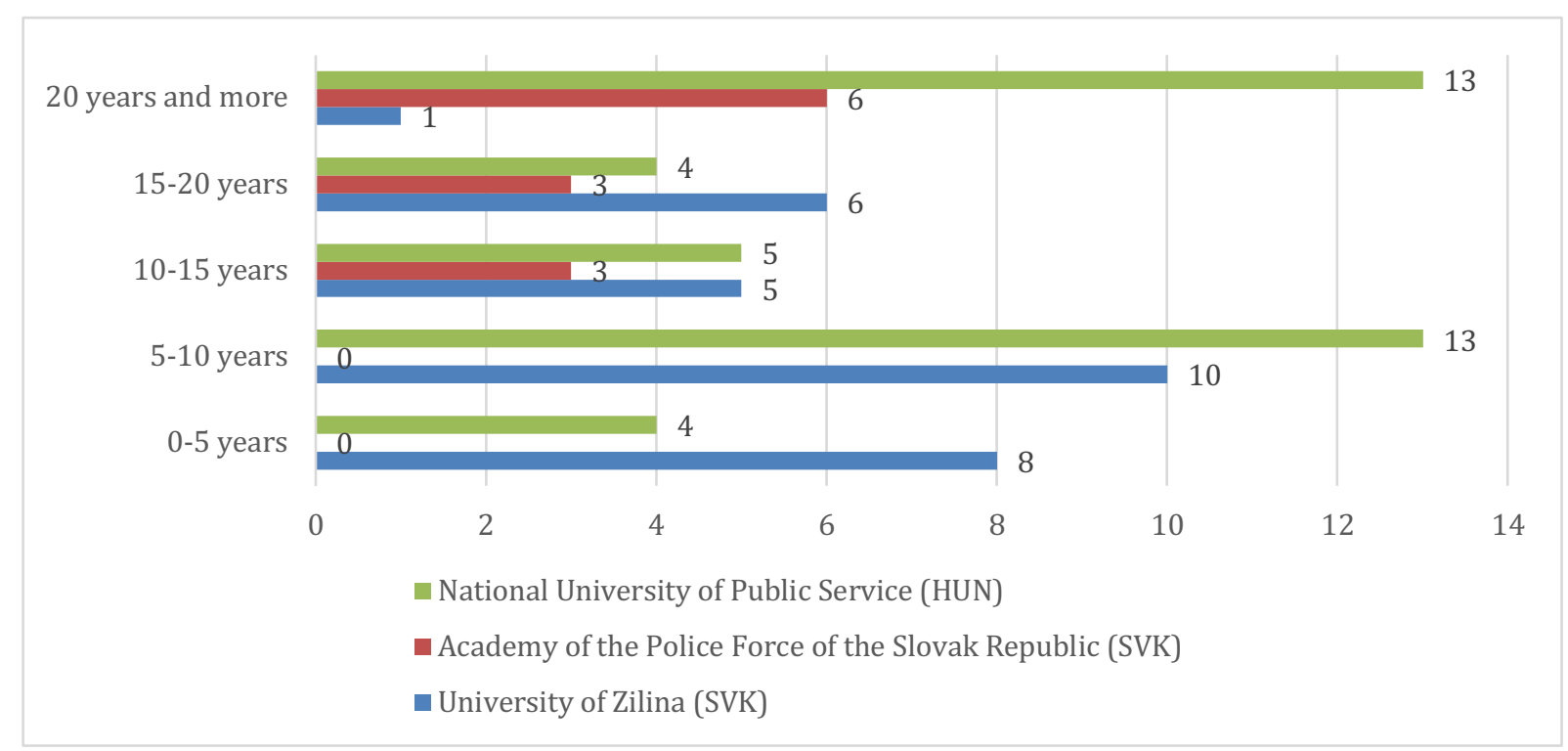

Figure 1 - Expression of pedagogical practice of respondents

As we can see from the results in Figure 1, the questionnaire was attended by respondents with different pedagogical practices. We can consider as the most represented group teachers with pedagogical experience 
between 5-10 years and 20 years and more. The academy of the police force of the Slovak Republic had the most respondents, with pedagogical experience of 20 years and more, and therefore we could assume a lower experience with modern technologies. From the University of Žilina in Žilina and the National University of Public Service, most respondents had pedagogical experience at the level of 5-10 years.

Another series of questions focused on how teachers and students communicate during a pandemic. In this case, we offered respondents a choice of predefined options. The question in the questionnaire was formulated whether they used, in addition to email, another method of communication, as we assumed email as commonly used during the classical form of teaching. The results obtained are shown in Figure $2[8-9]$.

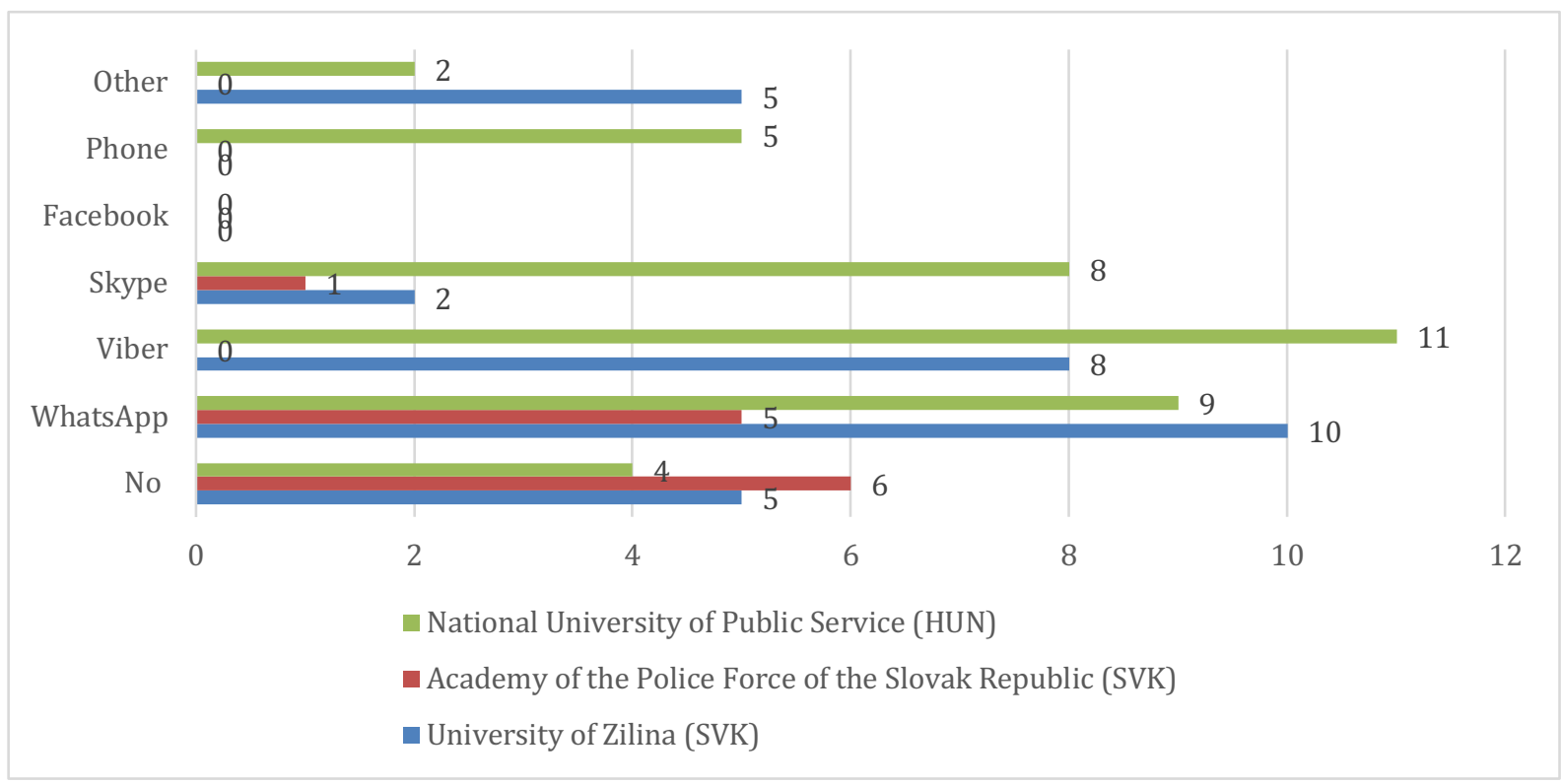

Figure 2 - Expression of the method of communication

As we can see from the results, the most frequently used way, apart from email, was Viber, as a total of 11 respondents saw this possibility. Interestingly, one respondent did not say a classic phone call. The question is whether the respondents have a business telephone number or have communicated with students through their private telephone numbers. It is gratifying that the vast majority have used online work programs which make it possible to observe a certain shift in higher education [10 - 11 - 12].

The online lecture program was the basis of the questionnaire survey and its results are shown in Figure 3. In this question, we again offered respondents the opportunity to choose from predefined, standardly used online programs.

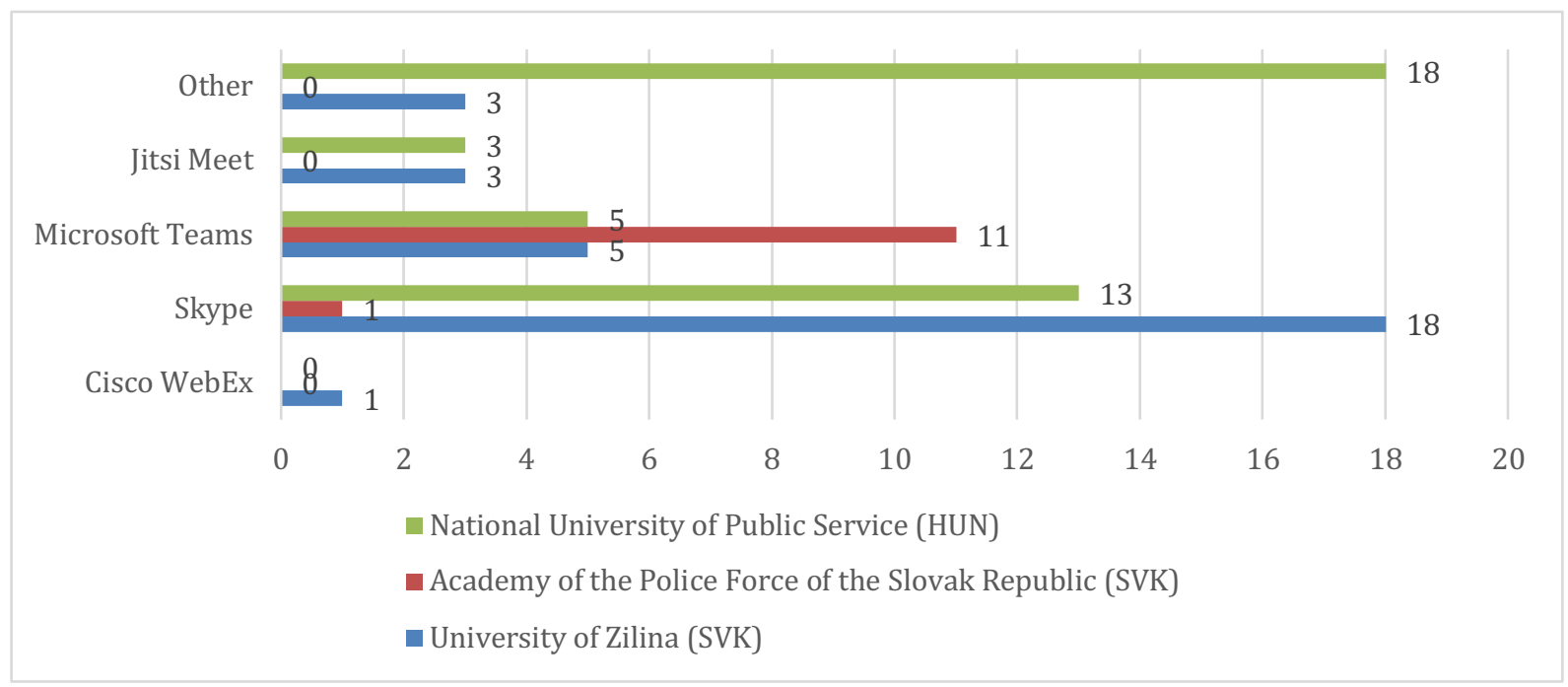

Figure 3 - Expression of the use of the online teaching program 
Based on the presented results, we can state that the most frequently used online program is Skype and MS Teams is closely related. With another series of questions, we focused on finding out why teachers started using the program they labeled. From the results, we can state that in the case of the Academy of the Police Corps it was an order of the institution. In the case of the National University of Public Service, these were the recommendations of colleagues, the respondents used mainly the Moodle and Neptune programs, which were not part of the predefined answers. In the case of the University of Žilina in Žilina, it was most often the Skype program recommended to teachers by a senior staff member or colleagues [3-13-14].

The last series of questions of the questionnaire was focused on the form of the implementation of the subject exam, while we were interested in whether there is a change in the form that arose due to the pandemic situation. It turned out that all universities prefer the oral form of the exam, as up to $78 \%$ of all respondents stated that they used this method of the exam before the pandemic. $19 \%$ of respondents stated that students take a written form of examination in their subject and only $3 \%$ stated another option. These cases were semester projects or laboratory exercises. It is very gratifying that they have maintained these values and the multitude even in a pandemic situation. In the case of a pandemic situation, there was a change and the oral exam through online programs was carried out by teachers in $74 \%$, the written exam through an online test was stated by respondents in $20 \%$ and another form was at the level of $6 \%$. In this case, another form was implemented mainly through the elaboration and submission of the assignment [5-15].

\section{CONCLUSIONS}

The paper aims to evaluate the mastery of distance learning in the summer semester of the academic year 2019/2020 at selected universities dealing with security education. For the evaluation, a questionnaire survey was conducted among teachers of these universities, which was attended by 81 respondents. The respondents work at universities in the Slovak Republic and Hungary. We also tried to get answers from a university in the Czech Republic, but without success.

The questionnaire survey was focused on finding out the pedagogical practice of the respondents, communication with students, the use of an online lecture program, and the form of taking the subject exam. Through the results, we can assess that the respondents who participated in the questionnaire survey managed a challenging pandemic period without major problems. On the positive side, in addition to the classic email communication, they also used modern forms such as Viber, WhatsApp. The absence of a classic telephone call remains interesting.

Despite the efforts from the results, it is not possible to say unequivocally which university best managed the situation of distance education. However, it is possible to express the unity of the employees of the University of Žilina in Žilina in the use of the video conferencing program Skype to provide teaching. A certain form of unity can also be seen in the case of the Academy of the Police Force, whose employees used the institution-recommended MS Teams program. We could see a certain uniformity in the case of the National University of Public Service, which used mainly Moodle and Neptune, but these programs are primarily intended for e-learning and not for online teaching, so we marked them as different in the evaluation.

It was also a gratifying finding that only in $8 \%$ there was a change in the form of the subject examination. This fact certainly directly affected the students who, despite the special situation and the distance form of teaching, did not feel the difference both in the form and in the subject exams. At present, it is necessary for us to each learn from the previous period and, from a preventive point of view, be prepared for a possible special situation again.

\section{ACKNOWLEDGEMENTS}

This paper was supported by project VEGA 1/0768/19.

\section{REFERENCES}

[1] T. Lovecek, A. Velas, K. Kampova, et al.," Cumulative Probability of Detecting an Intruder by Alarm Systems", 47th International carnahan conference on security technology (ICCST), IEEE, 2013 
[2] L. Hofreiter, Z. Zvakova," Theoretical Aspects of Critical Infrastructure Protection", International Conference on Durability of Critical Infrastructure, Monitoring and Testing (ICDCF), pp.139-147, 2017

[3] V. Soltes, Z. Stofkova, "Education of selected groups of the population in crime prevention ", 11th International Conference on Technology, Education and Development (INTED), pp. 6612-6617, 2017

[4] K. Kampova," The concept of social risks perception", 7th International Conference on Computer Simulation in Risk Analysis and Hazard Mitigation, 2010

[5] J. Simackova, K. Buganova," Risk management as a toool for increasing the success of innovative projects", Impact of industry 4.0 on job creation, pp. 397-404, 2020

[6] K. Buganova, M. Luskova, M. Hudakova," Early Warning Systems in Crisis Management", International conference on management innovation and business innovation (ICMIBI), Vol. 15, pp. 218-223, 2013

[7] L. Hofreiter, A. Byrtusova, Z.Zvakova, et. al.," Ontological Aspects of Security Protection”, 3rd International Conference on Management Innovation and Business Innovation (ICMIBI), Vol. 58, pp. 9-14, 2016

[8] A. Siser, V. Soltes, J. Kubas, "Crime prevention in to the education process at high schools ", 8th International Conference on Education and New Learning Technologies (EDULEARN), pp. 58035808, 2016

[9] J. Svetlik, J. Flachbart," The Crew Safety During Burning Car", 19th International Scientific Conference on Transport Means, pp. 599-602, 2015

[10] J. Stofkova, L. Maris, V. Soltes, "To the problem of information security within the local government “, 7th International Conference on Education and New Learning Technologies (EDULEARN), pp. 6629-6635, 2015

[11] K. Makka, K. Kampova," Workplace training within the field of prevention of accident management", 10th International Conference on Education and New Learning Technologies (EDULEARN), pp. 3276-3280, 2018

[12] V. Soltes, J. Kubas, K.R. Stofkova," Motivation of students in education in the field of security management, "12th International Technology, Education and Development Conference (INTED), pp. 9331-9337, 2018

[13] M. Masar, M. Hudakova," Project risk management in the context of industry 4.0 in condition of manufacturing enterprises in Slovakia", Impact on industry 4.0 in job creation, pp. 145-154, 2019

[14] V. Mitasova, V. Soltes, "Education of professionals for the international crisis management tasks' implementation ", 11th International Conference on Technology, Education and Development (INTED), pp. 6624-6629, 2017

[15] A. Siser, T. Lovecek, L. Maris, "Simulation of possible assault vectors in an attack using a real-life waterworks object as a use case ", 12th International scientific conference of young scientists on sustainable, modern and safe transport, Vol. 192, pp. 794-799, 2017 